\title{
Espectros postais: aproximações entre biografia crítica e correspondência de escritores
}

Silvana Moreli Vicente Dias (USP)

\begin{abstract}
Resumo
Este texto versa sobre a possibilidade de se aproximarem duas formas literárias distintas, a biografia crítica e a correspondência. O conceito que guia a proposta aventada é a do ensaio literário, de cunho interpretativo. Algumas perguntas lançadas procuram discutir em que medida uma biografia crítica poderia se nortear por cartas trocadas entre escritores, sobretudo quando publicadas postumamente. Uma das formas de "escritas de si", cartas podem sustentar narrativas comprometidas com as formas de vidas, desnudando seu caráter contingente. Nesse contexto, a matriz filológica pode ser retomada como maneira de se imprimir não só uma marca de fidedignidade, como também de se distinguir a ética do intérprete comprometido com a figuração autêntica do sujeito em questão.
\end{abstract}

Palavras-chave: Biografia crítica; Epistolografia; Gilberto Freyre.

\begin{abstract}
This text aims to discuss the possibility of convergence of two distinct literary forms, the "critical biography" and the correspondence. The concept that guides this proposal is the literary essay. Some questions will be presented, in order to consider in which measure a "critical biography" could largely use the correspondence among writers, mainly when published posthumously. One of the forms of "self-writing", letters may help to write narratives compromised with forms of lives, addressing what is substantially contingent. In this context, the philological matrix can be operated in order to reinforce not only the fidedignity of the text, but also the ethics of the essayist-biographer responsible for the authentic figuration of a character.
\end{abstract}

Keywords: Critical biography; Correspondence; Gilberto Freyre. 
1. LUKÁCS, Georg. Sobre a essência e a forma do ensaio: uma carta a Leo Popper, 2008.
Como introdução a essa discussão, caberia chamar a atenção para o fato de que uma biografia crítica, nos termos em que a compreendemos, poderia se imiscuir com a forma do ensaio literário. Mais ainda, podemos dizer que uma boa biografia crítica deve ser necessariamente ensaística, para além dos procedimentos de verificação documental e de inquirição persistente de fontes - apesar de tais cuidados serem componentes fundamentais para o alcance de bom resultado em um trabalho comprometido com a trajetória de sujeitos individuais. Uma das mais belas definições de "ensaio", meditada em carta para Leo Popper por Georg Lukács, trata o gênero ensaístico como algo que transcende a verdade objetiva:

É certo que o ensaio aspira à verdade: mas como Saul, que partiu para buscar as mulas de seu pai e encontrou um reino, também o ensaísta, que realmente está em condições de buscar a verdade, encontrará ao fim de seu caminho o objetivo não buscado, a vida. ${ }^{1}$

Nessa proposição de Lukács, convergem questões que nos interessam: trata-se de uma carta, escrita magistralmente, que, ao falar sobre o ensaio do ponto de vista estético, consegue despertar a alma na própria forma que anima. $\mathrm{Ou}$ seja, é uma carta-ensaio, que fala sobre a vida como sinônimo da matéria bem lograda esteticamente, o processo alçado à condição de arte.

Se, por um lado, podemos ficar seguros quanto ao pressuposto de que uma biografia crítica - ensaística - deveria ser mais fiel à ideia, a um conceito, do que ao seu conteúdo, ao seu referente, por outro lado tirar a oportunidade de que dialogue, de modo produtivo, com as fontes pode empobrecer a tensão que eventualmente determina a fecundidade de sua relação com o real. Lançar mão da correspondência de escritores pode ser, então, uma maneira de dinamizar o acesso a fontes documentais preciosas, ao mesmo tempo em que, se o biógrafo crítico for um bom orquestrador de vozes (se souber transmitir a polifonia dos tempo passado, cruzando com matérias do presente e lançando-se para o futuro), a apropriada fatura seria alcançada, sem duelar com outras eventuais escritas biográficas dedicadas ao mesmo sujeito.

Sem desprezar o trabalho acurado com as fontes - pelo contrário, necessariamente o implicando, por meio das notas, de leitura atenta de vasta bibliografia, da transcrição cuidadosa de documentos originais -, um pressuposto inevitável para a atual fase de pesquisas sobre as "escritas de si” engloba a noção de precariedade do sujeito, qualidade exponencialmente reforçada quando seus rastros são percorridos a partir de uma forma literária também precária, lacunar, performática (instaurada no 
hic et nunc da enunciação), híbrida, contingente, como é uma carta. Escrever uma biografia crítica seria buscar, com muito custo, alguma consistência em um emaranhado de vozes, imagens, sensações e palavras totalmente residuais - principalmente quando falamos de um autor já morto. Quando sabemos que esse autor pode ter ainda semeado pistas falsas, ou mesmo uma série de mapas contraditórios até sobre fatos aparentemente banais - como é o caso de Gilberto Freyre, autor com o qual trabalhamos há alguns anos -, a tarefa se complica sobremaneira. Por fim, se, adicionalmente, pressões conflitantes, vindas de diversas áreas de pesquisa, resultantes de uma especialização acadêmica surda para as necessidades alheias ao seu campo de saber, incidem sobre o biógrafo, o quadro delineado passa a ser desalentador. A menos que o intérprete seja mais estimulado do que abatido pelos grandes desafios.

Dedicar-se à escrita da vida de um sujeito, desde Friedrich Nietzsche, Roland Barthes e Gilles Deleuze - para citar autores emblemáticos nessa mudança de perspectiva -, passou a significar, de algum modo, inventá-la, animá-la, dar-lhe forma e substância renovadas. As imprecisões e ambiguidades levantadas por uma carta, nesse sentido, podem enriquecer adicionalmente uma biografia que se guia pela ideia de reinvenção póstuma da vida, que já não é a mesma - o sentido de origem está presente, mas logo seu monopólio é descartado para dar lugar ao inusitado, ao paradoxal, ao espectral das memórias fragmentadas. ${ }^{2}$

Alguns problemas deste ensaio já parecem postos: como animar, criativamente, a tensão entre vida e escrita a partir de fragmentos postais dispersos? Em que medida provocar positivamente a potência estética alimentada pela condição lacunar própria do texto epistolar? Seria possível afirmar que os resíduos postais contêm molduras autobiográficas que ativam a polifonia do texto biográfico resultante? Se raciocinarmos nesse caminho, a impureza da matéria biográfica saltaria aos olhos - o que necessariamente eclipsaria possíveis demandas exclusivas pela verossimilhança, pela cronologia, pela narrativa linear, pelo antigo conceito de história apegado à noção de conhecimento legitimado pela autoridade, e não pela experiência. ${ }^{3}$ Estaríamos, na trilha de Giorgio Agamben, caminhando mais em busca de uma nova temporalidade, descontínua, intervalar, que faz parte do diálogo em correspondência recuperado postumamente.

Nesse ponto, vale a pena endereçar a mesma problemática por outra via. Se a integridade do diálogo epistolar é algo de que é impossível escapar, o que lhe reconhecer como próprio? Sendo assim, caberia retomar alguns pontos de uma discussão já clássica quando se trata de matéria filológica. Existe algum lugar para onde se pode retornar em busca de alguma consis-
2. Apesar de não ser minha intenção radicalizar o tom da inventividade embutida nesta proposta biográfica a partir de "resíduos postais", vale a pena citar as palavras de Luciano Bedin da Costa, em torno da proposta barthesiana de "biografema": "Sabe, o biógrafo, que não se trata apenas de escrever. Sabe que, assim como as grandes filosofias, uma biografia também constitui novos mundos, na condição de dar-lhes uma certa consistência. Tanto em vidas para as quais documentos minguam histórias condenadas ao desaparecimento, quanto em vidas saturadas de testemunhos a vida dos grandes da História, o que há de ser registrado terá o tom dessa sismografia impossível, de uma zona de distanciamento entre o que se julga ter sido e o que se tem a dizer. Em outras palavras, a vida biografada não é puro reflexo de uma vida vivida, mas o vivido de um agora em ato presente." (COSTA, Luciano Bedin da. Biografema como estratégia biográfica: escrever uma vida com Nietzsche, Deleuze, Barthes e Henry Miller, 2010, p. 39).

3. Para Agamben, a experiência expropriada do homem enquadra-se no projeto de edificação da ciência moderna, passando a importar somente o que é certo, calculável, verificável. Nessa crítica de Agamben, é interessante como o autor propõe uma nova temporalidade baseada não na origem, na cronologia, mas no ponto de ruptura entre $o$ diacrônico e o sincrônico, do humano e do não-humano, da palavra e da infância. (AGAMBEN, Giorgio. Infância e história: destruição da experiência e origem da história, 2005). De certo modo, buscamos algo que se imponha como uma ruptura de universos estanques - resíduos ou fragmentos em movimento. 
4. TEZZA, Cristovão. $O$

espírito da prosa, 2012, p. 171. tência em matéria tão escorregadia - principalmente quando não há origem para a qual se apontar? Vale a pena procurar a experimentação da escrita de uma vida tomando por base fragmentos epistolares? Minha aposta é que o que se aponta como defeito pode ser sua virtude.

A percepção do paradoxo seria constitutiva do próprio gênero epistolar por uma obviedade flagrante: em primeiro lugar, uma carta é um testemunho movente, parte de um diálogo do qual é difícil precisar seu início e seu fim, bem como a totalidade de seus elementos intermediários. Mas não só. A reflexão do romancista Cristovão Tezza sobre a carta - e sua contiguidade com o romanesco - é incisiva: foi a solidão, o desamparo do indivíduo que criou o gênero epistolar moderno.

A carta, como gênero, é um breve e solitário combate do indivíduo. $\mathrm{O}$ poder literário moderno da composição epistolar está exatamente nesse ponto, e sua sobrevivência eventual depende dessa presença viva. ${ }^{4}$

Mais que algo gravado no próprio resíduo de uma carta que seria um reflexo projetado de maneira imperfeita, o advento da carta como forma, como performance, testemunha o embate do moderno indivíduo solitário. $\mathrm{O}$ remetente que se debruça sobre um pedaço de papel para falar sobre seus fracassos com seu destinatário, sobre suas dúvidas, sobre suas hesitações, já não é um sujeito moderno no sentido iluminista da palavra, mas um sujeito fraturado, que busca se compor quando o próprio sentido da existência parece lhe escapar inelutavelmente. O que vemos sugerido, com força poética, em carta inédita de Gilberto Freyre a José Lins do Rego, datada de "Recife, 31 de março de 1927", são os contornos de uma subjetividade que escapa:

Acabo de receber sua carta-sem data: aquela em que fala da visita ao velho Oiticica, num tão acolhedor engenho, bem à beira de um rio como deve ser todo engenho que se preza. Decididamente houve carta sua para mim que se perdeu-convindo que você registrasse suas cartas. Eu hoje já não me correspondo com quase ninguém, tenho deixado que a distância vá empalidecendo muita amizade feita por este mundo afora, onde tenho deixado alguma cousa de mim-pois sou, com todo o esforço em contrário, um mutilado. Se pareço inteiro, é a custa de recomposições de borracha. Mas isso para dizer o seguinte: que estimaria que também a sua amizade não fosse embora de minha vida, só por umas miseráveis léguas de um estadozinho do Brasil a outro. Não estranhe minhas demoras às vezes em escrever-falta de veneta, de ânimo, pois você bem sabe como em mim a alegria por assim dizer social é sempre ou quase sempre um esforço deliberado contra a acídia. Escreva-me sempre uma linha ou outra, acompanhando seus 
artigos, seus belos e fortes artigos desta sua nova fase, que tenho lido, graças à gentileza de Olívio, com um grande gozo e uma grande admiração. Você é de fato um dos talentos mais vivos e uma das imaginações mais ricas que tenho encontrado. Eu por aqui vou me arrastando, obrigado a Deus sabe por que-a encontrar diariamente muita gente, que entretanto recebo apenas nos batentes-nem na antessala-da minha sensibilidade. Mas neste meu cargo, achei uma função interessante-que é a das audiências públicas, onde o Governador, como bom senhor de engenho que apesar do fraque de bacharel continua a ser no interno, recebe tudo quanto é gente humilde, esta nossa boa gente humilde: e eu me dedico à defesa de causas dessa pobre gente, o que me vem dando um certo prazer cristão.

Contudo, na contemporaneidade, a percepção de que há espectros de sujeitos não se confunde com uma compreensão espectral do sujeito. ${ }^{5} \mathrm{O}$ desafio crítico poderia situar-se no intervalo do gesto, na "medialidade" pura e sem fim comunicada aos homens, recuperando Agamben. ${ }^{6}$ Logo, o gesto sem finalidade da escrita de uma carta, instantâneo de um ato de sedução intelectual que se instaura no âmago da ausência, parece conter algo de verdadeiro sobre a gestualidade no sentido empregado por Agamben. Publicar uma carta inédita ou mesmo recompô-la numa narrativa biográfica seria uma maneira de flagrar esse gesto, nem fim nem meio para se atingir uma finalidade, um modo inaugural de se ler a história.

Resta, agora, falar algo sobre a autenticidade do gesto biográfico - abandonando-se, pois, a questão da "verificabilidade" como algo primordial. Vários autores já se dedicaram ao tema do "retorno à filologia", grosso modo seja para defender o espaço da disciplina, seja para delimitar uma nova metodologia de investigação mais colada ao objeto sobre o qual se discorre, mais próxima à experiência com a palavra, com a linguagem - o que situaria a discussão no âmbito da teoria literária. Para nós, a filologia traduz, sem apartar, uma técnica e uma hermenêutica. Encontrar o equilíbrio na movência entre técnica e hermenêutica colaboraria decisivamente para a fatura de uma biografia crítica.

Em filologia, o problema da autenticidade é central, e essa e outras questões da disciplina tocam transversalmente o tema da biografia crítica e sua convergência com o texto epistolar. Mas antes de entrar no domínio do procedimento técnico da disciplina - que seria fundamental para a realização de uma biografia crítica com um mínimo de protocolo -, seria preciso fazer uma rápida discussão sobre como a relação entre filologia e interpretação literária é já uma relação antiga - o que parece reforçar, e não negar, o sentido etimológico primeiro de "amor às letras".
5. Segundo Agamben:

"[...] mas o que acontece agora é que processos de subjetivação e processos de dessubjetivação parecem tornarse reciprocamente indiferentes e não dão lugar à recomposição de um novo sujeito, a não ser de forma larvar e, por assim dizer, espectral. Na não-verdade do sujeito não há mais de modo algum a sua verdade" (AGAMBEN, Giorgio. O que é o contemporâneo?, 2009, p. 47).

6. Cf. AGAMBEN, Giorgio. Notas sobre o gesto, 2008, p. 9-14. 
7. SAID, Edward. Introdução a Mimesis, de Erich Auerbach, 2007a, p. 113.

8. AUERBACH, Erich.

Filologia da literatura mundial, 2007, p. 372.

9. Para Said: "Uma verdadeira leitura filológica é ativa: implica adentrar no processo da linguagem já em funcionamento nas palavras e fazer com que revele o que pode estar oculto, incompleto, mascarado ou distorcido em qualquer texto que possamos ter diante de nós" (SAID, Edward. O regresso à filologia, 2007B, p. 82).

10. Nas palavras de Paul de Man: "[...] la literatura, en lugar de enseñarse sólo como materia histórica y humanística, se debería enseñar como retórica y poética antes de enseñarse como hermenéutica e historia". [a literatura, em vez de ser ensinada como matéria histórica e humanística, deveria ser ensinada antes como uma retórica e uma poética e só depois como uma hermenêutica e uma história] (DE MAN, Paul. El regresso a la filologia, 1990, p. 46).

11. Como reflete Ivo Castro: "Nenhuma edição crítica é mais que uma 'proposta de trabalho', nenhuma encerra definitivamente a forma e a significação de um texto. A letra do texto não segrega um sentido literal. Assim como muito autor compartilha com outros participantes a responsabilidade final pela obra, assim nenhum filólogo trabalha liberto das condições do seu tempo. A transcrição é menos uma função do texto que do público a que se destina." (CASTRO, Ivo. $O$ retorno à filologia, 1995, p. 7).
Edward Said, no texto "Introdução a Mimesis, de Erich Auerbach”, tece uma crítica elogiosa acerca do estilo ensaístico singular do autor deste livro clássico da interpretação literária. Combinam-se, no filólogo, segundo Said, a erudição "sem espalhafato" e a "confiança paciente e amorosa na sua missão de erudito e filólogo". 7 O problema, portanto, não é fixar "definitivamente" um texto, mas lê-lo em sua complexidade, escrita que se move ao longo do tempo e que lega testemunhos diversos à humanidade. Said capta a confiança de Auerbach nas sedimentações profundas da história, o que dá substância e espessura ao realismo descrito pelo intelectual em seu Mimesis.

A missão humanista na linha abordada por Said seria obscurecida pelo advento da especialização crescente do pós-guerra. Nesse contexto, as "escritas de si" sofreriam, igualmente, um forte revés. Ao passo que Mimesis foi escrito em Istambul durante a Segunda Guerra Mundial e pode ser lido como a manifestação de uma confiança na densidade cumulativa da tradição cristã-judaica, outro texto do pensador, "Filologia da literatura mundial", desconfia do futuro da literatura herdada do Ocidente, a reboque da estandardização da cultura no planeta: "De qualquer modo, nossa pátria filológica é a Terra - a nação já não pode sê-lo."” O lugar para onde retornar remete, portanto, a toda uma tradição historicamente compartilhada e canônica. E, a despeito das diferenças entre as atitudes críticas de Auerbach e Said (mais descentralizada no caso deste), é interessante em ambos que o procedimento filológico contém uma leitura singular da experiência histórica, seja ela de imersão e compartilhamento ou de exílio. Segundo Said, a filologia seria mobilizada na esperança de uma via real para a compreensão humanista "no melhor e mais amplo sentido da expressão", atitude de abertura e resistência, detença. Ambos os críticos atualizam, portanto, um poderoso conteúdo humanista, comunitário, de afirmação do poder da interpretação literária, uma verdadeira leitura filológica ativa e responsável. ${ }^{9}$

Paul de Man, em O regresso à filologia, aprofunda a ideia de desencanto com os rumos da especialização crescente da crítica, que mergulha em esquemas teóricos esvaziados, os quais desnudariam, por sua vez, uma "visão niilista da literatura". O procedimento filológico seria apropriado, mais uma vez, para combinar-se a uma hermenêutica e a uma história. ${ }^{10} \mathrm{O}$ regresso a um modo de leitura mais demorado do texto, mais colado às palavras e menos aos esquemas generalizantes, seria, porém, uma tarefa desafiadora. De qualquer modo, nota-se que a filologia acaba por se tornar uma espécie de metáfora que traduz a disposição para uma leitura complexa do texto, para além do estético como ato puro, sendo também uma história 
intelectual, uma psicologia, uma ética, ao considerar os vários testemunhos de um texto legado pela tradição.

Assim, a filologia estaria no horizonte de um campo ao qual o intérprete - um biógrafo crítico - poderia se voltar para uma formulação de sentido mais colada a sua experiência histórica, sendo ao mesmo tempo movimento autêntico com relação às demandas do próprio texto de partida. Porém, uma vez que já implicaria um procedimento crítico - tendo em vista, no limite, a produção de textos fidedignos, mais próximos à última "vontade do autor", embora seu resultado jamais deixe de ser uma proposta de trabalho dentre outras possíveis ${ }^{11}$-, ela não pode significar uma hermenêutica destituída de parâmetros rigorosos, adormecida para a necessária distinção entre escritor e autor. ${ }^{12}$

A apreciação filológica passa, então, a traduzir a disposição para se compreender o texto como um processo, por definição, inacabado. Quando se trabalha com o texto epistolar publicado postumamente, tal incompletude se põe como forçosa, definitiva, inevitável. A falibilidade de sua fixação é incontornável. Todavia, o que poderia significar uma falha sem possibilidade de retorno ao procedimento filológico exato e delimitado pode ser criativamente lido como abertura a um preenchimento mediado pela figura do organizador, voz que se insinua criativamente no diálogo epistolar para torná-lo mais rico, em referências literárias, históricas, humanísticas. Nesse ponto, a proposta filológica flerta com a da crítica genética. Sobre essa questão, as palavras de Phillipe Willemart são incisivas:

[...] parece-nos mais claro que devemos orbitar em torno do texto publicado, qualquer que seja o campo em que trabalhamos. Chegar à interpretação do texto ou prepará-la deve ser o objetivo maior de todos os amantes do texto literário. Tanto quanto os campos afins - filosofia, psicanálise, sociologia -, a filologia e a crítica genética estão a serviço da interpretação do texto editado. ${ }^{13}$

Seja qual for o procedimento, já está dada de partida uma leitura, um compromisso com a presença radical do próprio texto. Garantir sua fidedignidade por meio de edições bem cuidadas do ponto de vista formal seria uma maneira de reforçar as possibilidades de transmissão e, consequentemente, de adensar a experiência de leitura. O campo da autenticidade é novamente tocado, mas por outras vias. ${ }^{14} \mathrm{E}$ o trabalho do estudioso que se debruça sobre o acervo pessoal de escritores sempre tende a produzir algo novo - o que remete novamente à ideia de performance. Sem ter muito claro o fim aonde chegar, o processo é o verdadeiro objetivo, o que resulta em um texto ensaístico por excelência. Assim, segundo Eneida Maria de Souza:
12. Para Philippe Willemart, "[...] a fonte principal da formação da obra se encontra na linguagem, na história, na tradição [e] a vida do escritor é apenas um dos elementos dessa formação". Mais adiante, Willemart convida para "esquecer a vontade do autor e falar em lógica do texto". (WILLEMART, Philippe.

A última vontade do autor, 1999b, p. 193-194).

13. WILLEMART, Philippe. $A$ filologia, a crítica genética e a interpretação do texto, 1999a, p. 203.

14. Nesse sentido, o texto "Sobre o retorno à filologia", da filóloga e membro da Academia Brasileira de Filologia Ceila Maria F. B. R. Martins, termina com uma atitude afirmativa que re-endereça, com propriedade, os desafios modernos do âmbito propriamente disciplinar: " $\mathrm{O}$ que é um texto? Quais são os seus limites? Qual é o texto que deve ser apresentado aos leitores: o texto livre das dúvidas, das hesitações, das pistas que levariam a um melhor entendimento do processo de escritura, o texto considerado definitivo pelo autor, ou o texto em construção? É possível apreender a totalidade da vontade do autor em relação ao texto? É possível reconstruir todo o processo de criação? Essas são algumas das perguntas enfrentadas pelos filólogos atualmente. E a Filologia se renova apesar das dúvidas e, também, por causa delas" (MARTINS, Ceila Maria Ferreira B. Rodrigues. Sobre o retorno à filologia, 2003, p. 10.). 
15. SOUZA, Eneida Maria

de. Crítica Genética e Crítica

Biográfica, 2009, p. 138.

16. Alguns trabalhos que retomam a condição limítrofe entre estético e prosaico são: BOUVET, Nora Esperanza. La escritura epistolar, 2006; ANGELIDES, Sophia. Carta e literatura: correspondência entre Tchékhov e Górki, 2001.

17. BOURDIEU, Pierre. $A$ ilusão biográfica, 1998.
É digno de nota o rico material existente nos acervos dos escritores, como a correspondência entre colegas, depoimentos, iconografias, entrevistas, documentos de natureza privada, assim como sua biblioteca, cultivada durante anos. Um esboço de biografia intelectual emana desses papéis, ao serem incorporados, ao texto em processo, a cronologia dos autores, o encarte de fotos, a reprodução de documentos relativos à sua experiência literária, assim como a revisão da bibliografia sobre os titulares das coleções. Essas pesquisas têm a qualidade de serem inéditas e originais, uma vez que o objeto de estudo é construído no decorrer do arranjo dos arquivos, da surpresa vivenciada a cada passo do trabalho. ${ }^{15}$

A filologia, apreendida na trilha de uma proposta que articule pesquisa em acervo e interpretação, mais que uma técnica de leitura do texto, revelaria uma ética do pesquisador diante da palavra do outro, legada caprichosamente pelo acaso de heranças que podem se insinuar, no limite, como espúrias. O texto epistolar é, de fato, muitas vezes um texto assinado, mas há inúmeros reveses que podem interferir até que ele seja preparado para constituir-se como um documento cultural e uma possibilidade estética genuína. ${ }^{16}$ Além da distância temporal que separa um texto editado do momento vivo de sua produção, um diálogo epistolar reconstruído postumamente jamais pode ser considerado definitivo, visto que inúmeros são os ruídos - resultando em polifonia - que podem interferir nessa transmissão cifrada. A feição que toma forma acaba se revelando, portanto, demasiado contingente. E um dos modos de se evitar a ilusão biográfica, ${ }^{17}$ uma estratégia persuasiva arquitetada pelo escritor, seria comprometer-se com os resíduos do processo que separa um documento de arquivo de sua divulgação póstuma, depurando-o, aos poucos, pacientemente.

Se, por meio da correspondência de escritores, lidamos com espectros de uma presença outrora viva, articular ensaisticamente a leitura desse "eu" com o outro - do "eu" que dialoga com seu destinatário - é uma possibilidade produtiva para a composição de biografias críticas, que se enriquece ainda mais quando articulada com a obra literária dos autores. Sobre essa proposta de "invenção" de biografias literárias, avança Eneida Maria de Souza:

A crítica biográfica, ao escolher tanto a produção ficcional quanto o documento do autor - correspondência, depoimentos, ensaios, crítica - desloca o lugar exclusivo da literatura como corpus de análise e expande o feixe de relações culturais. Os limites provocados pela leitura de natureza textual, cujo foco se reduz à matéria literária e à sua especificidade, são equacionados em favor do exercício de ficcionalização da crítica, no qual o próprio sujeito 
teórico se inscreve como ator no discurso e personagem de uma narrativa em construção. ${ }^{18}$

A transversalidade do método biográfico crítico, que toca universos díspares como a história, a sociologia, a psicanálise, a filosofia, a crítica da cultura, é ainda mais reforçada quando posta em cena uma forma literária indefinida como a carta, carregada de gestos ambíguos, situada na fronteira, no intervalo, um testemunho performático por excelência. Se a carta possibilita adensar a "leitura filológica" do documento - como busca pelo autêntico e como validade interpretativa -, de outro modo permite reviver o terreno das ambiguidades abissais próprias da palavra poética.

Encarada como, de certo modo, inventiva, atualizando perspectivas da crítica literária, situando-se como uma perquirição de forma e fundo ensaística, uma biografia de uma figura como Gilberto Freyre, ao operar sobretudo cortes epistolares, não viria para concorrer - o que seria uma pretensão até descabida - com livros sedimentados exemplarmente em seus terrenos de atuação, como Gilberto Freyre: um vitoriano nos trópicos, de Maria Lúcia Garcia Pallares-Burke (2005), ou Gilberto Freyre: uma biografia cultural, de Enrique Larreta e Guillermo Giucci (2007). ${ }^{19}$ Para um autor como Freyre, que sempre teve um pé na literatura, que queria ser reconhecido sobretudo como um ensaísta inventivo, é tentadora, inclusive, a ideia de lhe prestar um tributo lançando-o no centro do debate próprio à crítica literária - e transversalmente tocando uma ampla gama de saberes consolidados pela universidade moderna, de tradição humanista.

A proposta filológica confirma a aderência do texto ao chão histórico de sua produção, enquanto a proposta da biografia crítica se compromete com a busca de uma figuração crível do eu, autêntica, apesar de fragmentada, alimentada pelo paradoxo fundamental do texto que a sustenta. Esta pode, ain$\mathrm{da}$, guiar-se por questões centrais para a cena moderna brasileira, tais como, por exemplo, a indagação sobre como a escrita epistolar de Freyre permite compreender seu singular entendimento dos processos de modernização no país ou, ainda, a participação - e situar sua contribuição - nos debates polêmicos sobre província e metrópole, o regional e o nacional, em uma época marcada, como nunca até então, pela multiplicidade díspar de projetos estéticos, intelectuais e culturais em gestação.

A leitura empenhada com as possibilidades de transmissão pode, assim, conduzir o ensaio resultante para além do biografismo plano, monofônico, certo do caminho aonde chegar, da concepção de texto que traça a origem precisa e define, sem duvidar, a última vontade de um autor. Abrindo-se para a contingência, trata-se, acima de tudo, de uma forma biográfica
18. SOUZA, Eneida M. de. Notas sobre a crítica biográfica, 2002, p. 105.

19. Acredito, inclusive, que a "biografia cultural" de Larreta e Giucci não foi devidamente reconhecida. Compará-la ao elogiado livro de Pallares-Burke sob a ótica da crítica às fontes poderia ofuscar esse trabalho - e isso parece ter acontecido, o que se agravou pela própria recepção desconfiada que se seguiu às resenhas de Peter Burke e Pallares-Burke no caderno Mais! da Folha de S. Paulo. A biografia de Larreta e Giucci é, sem dúvida, cumulativa. Cita fontes à exaustão, muitas vezes sem precisá-las (embora não seja difícil, para um leitor acostumado a esse tipo de escrita e ao texto de Freyre, remeter-se ao documento original). A perspectiva de Pallares-Burke é, de outro modo, depurada, suas remissões são escrupulosas. A de Giucci e Larreta - lembrando, de certo modo, a Babel metodológica de Freyre - é um passeio pelos saberes já acumulados sobre o sociólogo, ao mesmo tempo em que divulga, numa escrita sem maiores contornos estilísticos, um amplo rol de artigos do escritor inéditos em livro, trechos de correspondência inédita, outras crônicas cotidianas sobre a polêmica figura. Um estudioso da obra de Freyre não pode deixar de ler, atentamente, ambos os livros. 
crítica que lança mão de um texto lacunar e plural, a fim de firmar-se também como processo inacabado, tortuoso, convite para a leitura ativa e - por isso mesmo, se bem logrado - cheio de novas potencialidades e sugestões. 


\section{Referências}

AGAMBEN, Giorgio. Notas sobre o gesto. In: Artefilosofia, n. 04. Trad. Vinícius Nicastro Honesko. Ouro Preto, 2008.

Infância e história: destruição da experiência e origem da história. Trad. Henrique Burigo. Belo Horizonte: Editora UFMG, 2005.

O que é o contemporâneo? e outros ensaios. Trad. Vinícius

Nicastro Honesko. Chapecó: Argos, 2009.

ANGELIDES, Sophia. Carta e literatura: correspondência entre Tchékhov e Górki. São Paulo: Editora da Universidade de São Paulo, 2001.

AUERBACH, Erich. Filologia da literatura mundial. In: Ensaios de literatura ocidental. Org. Davi Arrigucci Jr. e Samuel Titan Jr. Trad. Samuel Titan Jr. e José Marcos Mariani de Macedo. São Paulo: Duas Cidades, Ed. 34, 2007. Mimesis. A representação da realidade na literatura ocidental.

Trad. George Bernard Sperber. São Paulo: Perspectiva, 1971.

BOURDIEU, Pierre. A ilusão biográfica. In: FERREIRA, M. M.; AMADO, J. (Org.) Usos \& abusos da história oral. Rio de Janeiro: Ed. Fundação Getúlio Vargas, 1998.

BOUVET, Nora Esperanza. La escritura epistolar. Buenos Aires: Editorial Universitaria de Buenos Aires (EUDEBA), 2006.

CASTRO, Ivo. O retorno à filologia. Disponível em: <http:// www.clul.ul.pt/files/ivo_castro/1995_Retorno__Filologia. pdf>. Acesso em: 20 set. 2012.

COSTA, Luciano Bedin da. Biografema como estratégia biográfica: escrever uma vida com Nietzsche, Deleuze, Barthes e Henry Miller. Porto Alegre: Universidade Federal do Rio Grande do Sul, 2010. (Tese de doutorado em Educação).

DE MAN, Paul. El regreso a la filologia. In: . La resistencia a la teoría. Madrid: Visor Distribuiciones, 1990.

GIUCCI, Guillermo; RODRÍGUEZ LARRETA, Enrique. Gilberto Freyre: uma biografia cultural: a formação de um intelectual brasileiro: 1900-1936. Trad. Josely Vianna Baptista. Rio de Janeiro: Civilização Brasileira, 2007.

LUKÁCS, Georg. Sobre a essência e a forma do ensaio: uma carta a Leo Popper. In: Revista UFG, ano IX, n. 04. Trad. Mario Luiz Frungillo. Goiânia, 2008. Disponível em: <http://www.proec.ufg.br/revista_ufg/junho2008/Textos/ 
essenciaFormaEnsaio.htm>. Acesso em: 10 out. 2012.

MARTINS, Ceila Maria Ferreira B. Rodrigues. Sobre o retorno à filologia. 2003. p.1-10. Disponível em: < http:// www.filologia.org.br/viicnlf/anais/caderno10-16.html>. Acesso em: 10 out. 2012.

PALLARES-BURKE, Maria Lúcia Garcia. Gilberto Freyre: um vitoriano dos trópicos. São Paulo: Editora UNESP, 2005.

SAID, Edward. Introdução a Mimesis, de Erich Auerbach. In: ___. Humanismo e crítica democrática. Trad. Rosaura Eichenberg. São Paulo: Companhia das Letras, 2007a.

O regresso à filologia. In: Humanismo e crítica democrática. Trad. Rosaura Eichenberg. São Paulo: Companhia das Letras, 2007b.

SOUZA, Eneida Maria de. Crítica Genética e Crítica Biográfica. In: Patrimônio e história, v.4, n.2, São Paulo: UNSP, 2009.

Notas sobre a crítica biográfica. In: Crítica cult. Belo Horizonte: Editora UFMG, 2002.

TEZZA, Cristovão. O espírito da prosa. Rio de Janeiro: Record, 2012. WILLEMART, Philippe. A filologia, a crítica genética e a interpretação do texto. In: Bastidores da criação literária. São Paulo: Iluminuras, 1999a.

A última vontade do autor. In: Bastidores da criação literária. São Paulo: Iluminuras, 1999b. 